\title{
SOSIALISASI BERINTERNET SEHAT DAN AMAN UNTUK REMAJA DI KECAMATAN CIHIDEUNG KOTA TASIKMALAYA JAWA BARAT
}

\author{
Sulidar Fitri ${ }^{1}$, Hani Rubiani ${ }^{2}$, Windi Astuti $^{3}$ \\ ${ }^{123}$ Universitas Muhammadiyah Tasikmalaya \\ Email: sfitri@umtas.ac.id ${ }^{1}$, hani.rubianti@umtas.ac.id², windiastuti@umtas.ac.id ${ }^{3}$
}

\begin{abstract}
ABSTRAK
Dampak dari seseorang mengakses internet adalah hal yang negatif dan bisa juga menjadi hal yang positif, namun hal tersebut bukanlah menjadi suatu hambatan masyarakat kita untuk maju dalam mengikuti perkembangan teknologi informasi. Untuk mengurangi dampak negative dari kegiatan penggunaan akses internet dibutuhkan sosialiasi berinternet secara sehat dan aman. Sosialisasi yang akan dilakukan di daerah kecamatan Cihideung terbilang tepat karena di daerah tersebut terdapat beberapa sekolah seperti SMA (SMA Plus Nurul Arif Salam), sekolah SMP (SMP Plus Nururl Arif Salam), dan Ishlahul Ummah Boarding School. Secara demografis tepat dikatakan bahwa daerah kecamatan Cihideung memiliki anak remaja berstatus pelajar yang cukup banyak dan menjadi perhatian penting. Berdasarkan situasi para remaja berstatus pelajar yang ada di daerah kecamatan Cihideung yang membutuhkan perhatian khusus dalam hal berinternet, maka disini ditawarkan solusi berupa "Sosialisasi Berinternet Sehat dan Aman". Setelah dilakukan sosialisasi terlihat bahwa para remaja sangat antusisas dengan materi konten situs ataupun media sosial yang sehat dan positif sehingga diharapkan bisa diadakan lagi untuk di waktu mendatang.
\end{abstract}

Kata Kunci: Internet, Remaja, Internet Sehat, Internet Aman, Sosialisasi.

\begin{abstract}
The impact of someone accessing internet is a negative thing and can also be a positive thing, but it becomes an obstacle for us to move forward in the development. To reduce the negative impact of internet access usage activities required healthy and safe online when surfing online. The socialization will be conducted in Cihideung sub-district is appropriate because there are some schools like SMA (SMA Plus Nurul Arif Salam), Junior High School (SMP Plus Nururl Arif Salam), and Ishlahul Ummah Boarding School. Demographically right in the sub-district of Cihideung has teenagers and children with enough student status and become an important concern. Based on situation of the students in Cihideung sub-district, they need special attention in terms of surfing, then the following is an alternative "Healthy and Safe Internet Socialization". After the socialization, the teenagers were very enthusiast with material content or social media sites healthy and positive so that can be expected again to be held in the future time.
\end{abstract}

Keywords: Internet, Teenager, Healthy internet activity, online surf safe, Socialization 


\section{PENDAHULUAN}

Pendidik yang merupakan orang beilmu perlu mengaktualisasikan diri secara keilmuan melalui kegiatan Pengabdian Kepada Masyarakat (PKM) dimana PKM merupakan jembatan dunia pendidikan dengan masyarakat begitupula para pendidiknya yang membutuhkan wadah untuk menularkan ilmu pengetahuan yang dimiliki. Dalam hal ini masyarakat merupakan sasaran yang penting untuk dapat merasakan manfaat dari keilmuan dari para pendidikn yang butuh untuk ditularkan.

Pada era teknologi canggih seperti sekarang ini tidak dapat dipungkiri lagi bahwa internet sudah menjadi kebutuhan primer masyarakat kita di Indonesia. Berdasarkan data statistic hasil survey APJII (Asosiasi Penyelenggara Jasa Internet Indonesia) pada tahun 2016 tercatat bahwa sebesar 51,8\% atau sebanyal 132,7 orang dari total populasi penduduk Indonesia 256,2 juta orang menggunakan internet secara aktif (APJII, 2016). Sebanyak 6,3\% atau 8,3 juta orang adalah berstatus pelajar(isparmo, 2016).

Berdasarkan hasil wawancara terhadap remaja berstatus pelajar di daerah kecamatan Cihideung didapatkan bahwa 7 dari 10 remaja menggunakan internet hampir setiap hari dari bangun tidur sampai tidur lagi dengan jam online yang cukup sering. Sebanyak 5 remaja diantara 10 remaja berstatus pelajar menggunakan internet untuk mengakses situs dewasa baik secara sengaja maupun tidak sengaja. Beberapa diantara remaja pelajar tersebut sering melakukan tindak kekerasan terhadap temannya sendiri walaupun tidak parah dikarenakan sering mengakses permainan game online yang banyak menyajikan aktifitas kekerasan.

Fenomena nyata yang terjadi di daerah tersebut mengenai tindakan remaja pelajar cukup memunculkan keprihatinan bagi para pendidikan di dunia pendidikan kita. Tindakan yang mulai keluar dari jalur harus diberi perhatian kusus dengan cara membeikan sosialis untuk berinternet sehat dan aman sehingga tidak mengganggu perkembangan jiwa para remaja di daerah kecamatan Cihideung tersebut sebelum terjadi hal-hal yang tidak diinginkan.

Dampak dari seseorang mengakses internet bisa negatif dan bisa pula positif, namun hal tersebut bukanlah menjadi suatu hambatan masyarakat kita untuk maju dalam mengikuti perkembangan teknologi informasi. Untuk mengurangi dampak negative dari kegiatan penggunaan akses internet dibutuhkan sosialiasi berinternet secara sehat dan aman. Sosialisasi yang akan dilakukan di daerah kecamatan Cihideung terbilang tepat karena di daerah tersebut terdapat beberapa sekolah seperti sekolah SMA (SMA Plus Nurul Arif Salam), sekolah SMP (SMP Plus Nururl Arif Salam), dan Ishlahul Ummah Boarding School. Secara demografis tepat dikatakan bahwa daerah kecamatan Cihideung memiliki anak remaja berstatus pelajar yang diperkirakan cukup banyak sehingga menjadi perhatian penting.

Berdasarkan hasil analisis situasi yang sudah dipaparkan, maka beberapa permasalahan mitra di daerah kecamatan Cihideung diantaranya adalah sebagai berikut:

1. Bagaimanakah intensitas pemanfaatan internet para remaja berstatus pelajar di daerah tersebut?

2. Apa saja dampak positif pemanfaatan internet para remaja berstatus pelajar di daerah tersebut?

3. Apa saja dampak negatif pemanfaatan internet pada para remaja berstatus pelajar di daerah tersebut?

4. Seberapa banyak remaja yang terkena dampak negatif dengan porsi lebih banyak?

5. Bagaimana menangani dan mengantisipasi dampak negatif dari internet jika setelah dilakukan analisis situasi terdapat beberapa anak yang melakukan tindak kekerasan dan mengakses situs dewasa?

\section{BAHAN DAN METODE}

Berdasarkan situasi para remaja berstatus pelajar yang ada di daerah kecamatan Cihideung yang membutuhkan perhatian khusus dalam hal berinternet, maka disini metode yang dilakukan 
adalah mengadakan "Sosialisasi Berinternet Sehat dan Aman" langsung kepada remaja tersebut dengan cara melakukan ceramah sebagai pembicara di kelas.

Bahan berupa ketersediaan materi dalam bentuk file kertas maupun soft file juga digunakan untuk melengkapi alat kesiapan dalam kegiatan sosialisasi. Dalam penyampaian diusahakan untuk memberikan kesan bersahabata dan menjalin kedekatan dalam hal komunikasi dengan para remaja tersebut.

Materi yang akan dibagikan dan disampaikan diambil dari materi untuk berinternet sehat, cerdas, dan aman dari komunitas seperti internetsehat.org (Kalamkata, 2013), komunitas ICT Watch, IDKita Kompasiana, Yayasan Kita dan Buah Hati, dan dari materi anjuran oleh Kominfo (Kementrian Komunikasi dan Informasi) yang merupakan program INSAN (Internet Sehat dan Aman) (KOMINFO, 2013).

Untuk mengetahui hasil secara konkrit target luaran dari para remaja berdasarkan poin-poin diatas maka akan dilakukan survey setelahnya yang akan menghasilkan angka statistic yang jelas serta deskripsi yang mendukung hasil luaran survey tersebut.

Selain target luaran untuk para remaja tersebut, hasil dari kegiatan Pengabdian Kepada Masyarakat(PKM) ini juga akan disusun dalam bentuk jurnal dan dipublikasikan pada jurnal Abdimas Umtas. Sehingga hasil tersbut dapat dijadikan pelajaran dan pengetahuan untuk masyarakat secara luas.

Dari kegiatan sosialisasi yg dilaksanakan, maka ada target luaran yang diharapkan yaitu:

1. Para remaja tersebut paham mengenai apa saja situs maupun konten media yang positif dan baik untuk diakses dalam berinternet.

2. Para remaja bisa paham efek yang ditimbulkan setelah mereka berinternet dengan berbagai macam tujuan.

3. Para remaja paham mengenai ancaman apa saja yang mengintai ketika menggunakan internet.

\section{HASIL}

Kegiatan "Sosialisasi Berinternet Sehat dan Aman" ini dilaksanakan pada hari Kamis, 8 Juni 2017 pukul 16.00 WIB setelah jam pembelajaran resmi sekolah selesai. Di salah satu ruang kelas Ishlahul Ummah Boarding School daerah kecamatan Cihideung, kegiatan tersebut berjalan dengan lancar dan diikuti oleh para remaja dengan antusias.

Selain mengisi kegiatan sosialisasi dengan memberikan pemaparan mengenai berinternet sehat, kegiatan ini juga dilakukan pembagian selebaran yang berisi informasi singkat dari materi yang telah dipaparkan beserta angket dari tim pengabdian masyarakat UMTAS untuk mengetahui hasil evaluasi secara deskriptif dampak dari sosialisasi yang telah dilakukan.

Selama kegiatan sosialisasi berlangsung terlihat wajah-wajah antusias dari para remaja yang mengikuti pemaparan yang diberikan. Sesekali beberapa remaja menanyakan hal-hal yang dianggap menarik seperti situs-situs maupun media sosial menarik yang bisa dikunjungi dan memiliki konten positif namun ringan dalam pengaksesan datanya dikarenakan tidak semua remaja memilik akses internet yang kencang.

Kegiatan sosialisasi ini mendapat sambutan yang sangat baik, berdasarkan hasil wawancara dengan peserta mengenai tanggapan mereka atas terselenggaranya kegiatan sosialisasi ini diperoleh hal-hal sebagai berikut :

1. Materi Berinternet Sehat dan Aman yang disampaikan oleh tim pengabdian masyarakat dari Universitas Muhammadiyah Tasikmalaya sangat menarik dan para remaja merasa mendapatkan wawasan tambahan mengenai perkembangan Dunia teknologi informasi yang sedang berkembang sekarang ini.

2. Kegiatan sosilasi oleh peserta dinilai sangat bermanfaat sehingga mereka mengharapkan agar ada kegiatan lanjutan yang berkaitan dengan Dunia teknologi informasi.

3. Perkembangan teknologi yang sangat pesat membuat mereka jadi lebih sadar untuk terus mengembangkan diri dari sisi ilmu pengetahuan dan informasi. 
4. Para remaja merasa harus lebih siap dalam menghadapi perubahan apapun secara global dan memeprsiapkan diri dalam mensikapi perubahan tersebut.

Selain hasil wawancara kepada para remaja, akan dijelaskan hasil survey dengan menggunakan angket setelah dilaksanakannya kegiatan sosialisasi berinternet sehat. Data yang dikoleksi sebanyak 50 sampel dari para remaja yang mengikuti sosialisasi dan para teman-teman remaja sedaerah yang mendapatkan selebaran informasi berinternet sehat. Dari gambar 1 bisa dilihat bahwa angka prosentase mengacu pada hasil koleksi data dari angket yang disebar pada para remaja setelah mengikuti kegiatan sosialisasi.

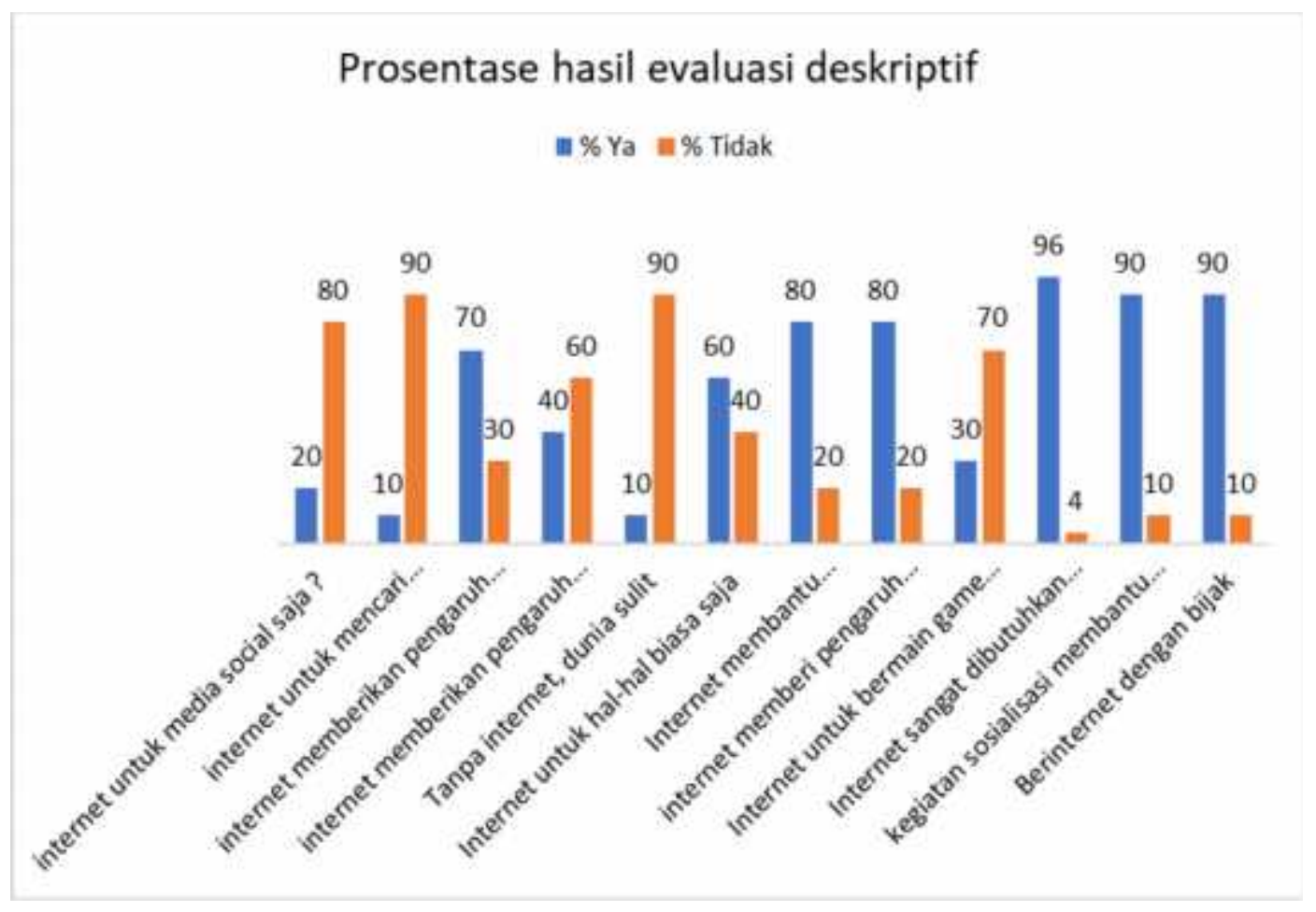

Gambar 1 Hasil evaluasi sosialisasi

\section{PEMBAHASAN}

Angka prosentase tertinggi ditunjukan oleh butir pertanyaan yang menyatakan 96\% remaja sepakat bahwa internet sangat dibutuhkan dalam kehidupan. Sedangkan angka prosentase terendah dari grup jawaban sepakat 'ya' ditunjukan oleh $10 \%$ remaja yang sepakat bahwa internet tidak banyak digunakan untuk mencari bahan pelajaran dan $10 \%$ remaja sepakat bahwa tanpa internet maka dunia akan kesulitan.

Berdasarkan hasil evaluasi yang telah dijelaskan maka kegiatan sosialisasi atau penyuluhan sejenis ini perlu terus dilakukan sesuai dengan perkembangan teknologi dan kebutuhan sosial remaja dalam menyikapi perkembangan zaman yang sering melibatkan teknologi informasi.

Kegiatan dalam belajar di kelas yang ada saat jam pelajaran sehari hari di kelas memberikan para remaja dorongan dan memicu para remaja untuk bisa memanfaatkan kecanggihan teknologi informasi dalam hal mendapatkan informasi untuk pengetahuan namun kurang dilengkapi dengan cara mensikapi perubahan yang luar biasa dalam perkembangan teknologi tersebut dari sisi keamanan dan kesehatan dalam menyerap keberagaman informasi yang banyak tersebar. 


\section{KESIMPULAN DAN SARAN}

Kegiatan Sosialisasi ini memberikan wawasan tambahan bagi para remaja di daerah kecamatan Cihideung Kota Tasikamalaya berkenaan dengan aktifitas online di dunia maya. Mereka sangat antusias mengikuti kegiatan tersebut. Pemahaman akan pentingnya sikap dalam melakukan aktifitas di dunia maya pun memberikan tambahan pembelajaran bagi mereka agar lebih bijak berselancar di dunia maya. Selama kegiatan berlangsung, beberapa dari para remaja memberikan kesan yang positif dan berkomitmen untuk bisa memanfaatkan internet dengan hal-hal yang lebih positif dan bermanfaat untuk kebutuhan pembelajaran maupun kebutuhan penunjang lainnya terkait dengan informasi. Latar belakang sekolah dari para peserta remaja pun berbeda, ada yang berbasis pondok pesantren yang menekankan pada Pendidikan agama maupun sekolah umum yang lebih banyak menekankan pada pelajaran-pelajaran umum. Meskipun latar belakang sekolah yang berbeda, mereka juga memiliki kesadaran akan pentingnya informasi dan pentingnya mengikuti tren teknologi terkini sehingga kegiatan sosilisasi ini memberikan tambahan pembelajaran sikap dalam hal merespon kecanggihan teknologi informasi.

Saran untuk kegiatan ini adalah agar bisa dilakukan lagi untuk memberikan wawasan tambahan bagi para remaja sehingga mudah untuk mengikuti perkembangan informasi maupun teknologi terkini. Mengingat laju perkembangan teknologi yang sangat cepat, maka butuh penyebaran infromasi yang lebih cepat pula ke masyarakat.

\section{UCAPAN TERIMA KASIH}

Dalam paragraf ini dihaturkan ucapan terimakasih kepada 1) Pihak Universitas Muhammadiyah Tasikmalaya yang telah memberikan dukugan berupa dana untuk kelancaran terlaksananya kegiatan pengabdian masyarakat ini, 2) Pihak Lembaga Penelitian dan Pengabdian Masyarakat (LPPM) yang telah memberikan dukungan serta bantuan dalam hal pembuatan proposal, laporan, maupun arahan dalam pengadaan kegiatan pengabdian masyakarat kami, 3) Pihak guru-guru Ishlahul Ummah Boarding School yang telah memberikan izin untuk diadakannya kegiatan ini, 4) Para Siswa yang merupakan remaja yang menjadi peserta dalam kegiatan ini, 5) Para rekan maupun tim sebagai pelaksana dalam kegiatan sosialisasi ini yang telah memberikan dukungan berupa dana, tenaga maupun pikiran untuk terlaksananya acara sampai selesai.

\section{DAFTAR PUSTAKA}

APJII. 2016. Asosiasi Penyelenggara Jasa Internet Indonesia. Retrieved January 24, 2017, from https://www.apjii.or.id/

Isparmo. 2016, November 21. Data Statistik Pengguna Internet Indonesia Tahun 2016 Pembicara Internet Marketing SEO \| Pakar. Retrieved January 30, 2017, from https://isparmo.web.id/2016/11/21/data-statistik-pengguna-internet-indonesia-2016/

Kalamkata. 2013. Internet Sehat. Retrieved January 30, 2017, from http://kalamkata.org/2011/02/20/pedoman-berekspresi-online/

KOMINFO, P. 2013. Internet Sehat dan Aman (INSAN). Retrieved January 30, 2017, from https://kominfo.go.id:443/index.php/content/detail/3303/Internet-Sehat-dan-Aman--

INSAN-/0/internet_sehat 


\section{LAMPIRAN}

\section{Contoh angket setelah kegiatan sosialiasi}

\section{Tabel 1 Angket evaluasi peserta}

\begin{tabular}{|c|c|c|}
\hline Pertanyaan & Ya & Tidak \\
\hline $\begin{array}{l}\text { 1.Apakah anda lebih sering menggunakan internet untuk } \\
\text { media social saja? }\end{array}$ & & \\
\hline $\begin{array}{l}\text { 2.Apakah anda lebih sering menggunakan internet untuk } \\
\text { mencari informasi tentang pembelajaran anda? }\end{array}$ & & \\
\hline $\begin{array}{l}\text { 3.Apakah menurut anda internet memberikan pengaruh positi } \\
\text { lebih besar? }\end{array}$ & & \\
\hline $\begin{array}{l}\text { 4.Apakah menurut anda internet memberikan pengaruh } \\
\text { negatif lebih besar? }\end{array}$ & & \\
\hline $\begin{array}{l}\text { 5.Apabila tidak ada internet dalam kehidupan anda, apakah } \\
\text { anda merasa kesulitan dalam segala hal ? }\end{array}$ & & \\
\hline $\begin{array}{l}\text { 6.Apakah anda lebih sering menggunakan internet untuk hal- } \\
\text { hal yang biasa-biasa saja? }\end{array}$ & & \\
\hline $\begin{array}{l}\text { 7.Apakah dengan adanya internet itu sendiri bisa membantu } \\
\text { anda dalam menyelesaikan masalah? }\end{array}$ & & \\
\hline $\begin{array}{l}\text { 8.Apakah internet memberikan pengaruh yang besar pada } \\
\text { kehidupan anda sendiri atau dunia? }\end{array}$ & & \\
\hline $\begin{array}{l}\text { 9.Apakah anda lebih sering menggunakan internet untuk } \\
\text { bermain game online? }\end{array}$ & & \\
\hline $\begin{array}{l}\text { 10.Dari pertanyaan di atas, apakah menurut anda internet itu } \\
\text { sangat dibutuhkan dalam hidup anda? }\end{array}$ & & \\
\hline $\begin{array}{l}\text { 11. Apakah kegiatan sosialiasai berinternet sehat ini } \\
\text { membantu pemahaman anda tentang dampak internet? }\end{array}$ & & \\
\hline $\begin{array}{l}\text { 12. Apakah Ke depannya anda akan melakukan kegiatan } \\
\text { berinternet dengan bijak? }\end{array}$ & & \\
\hline
\end{tabular}




\section{Bukti Foto Pelaksanaan Kegiatan}

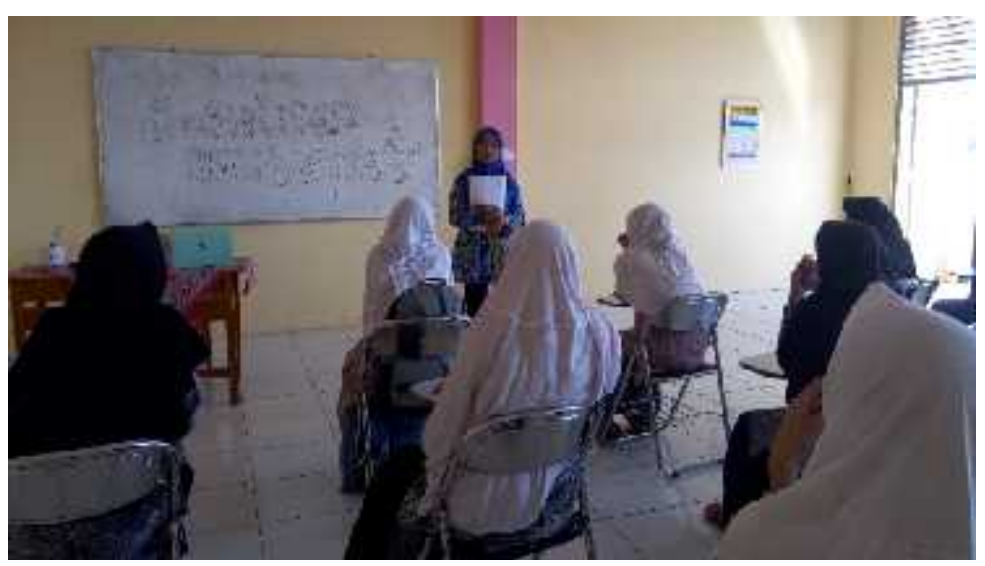

Gambar 2. Saat kegiatan sosialisasi berlangsung

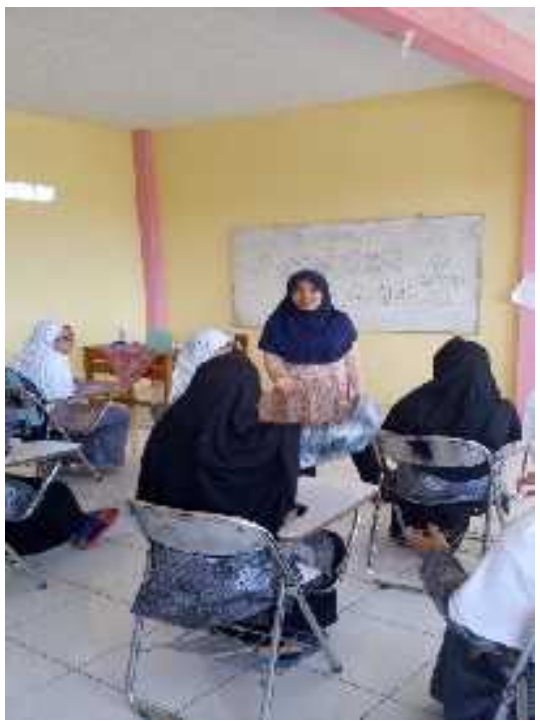

Gambar 3. Remaja yang antusias dan

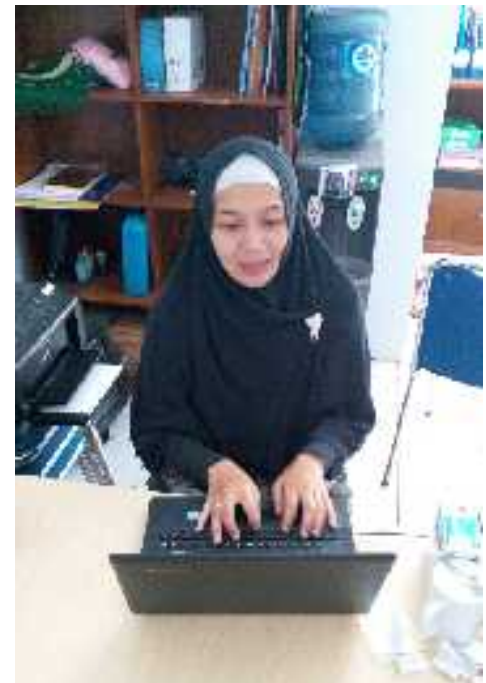

Gambar 4. Mempersiapkan materi

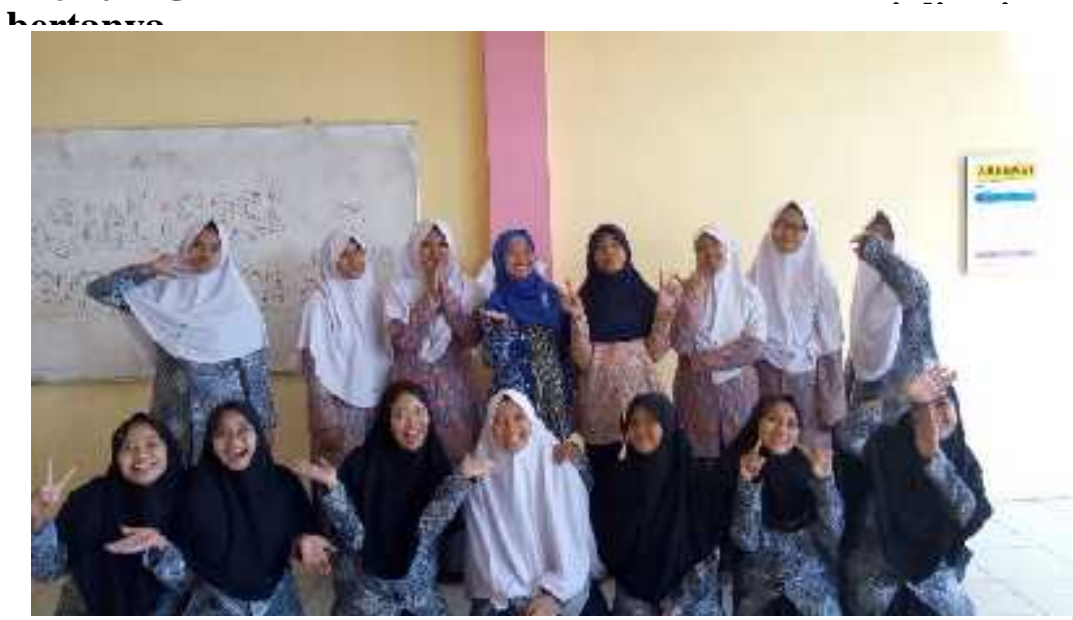

Gamabr 5. Setelah selesai acara sesi foto yang minat foto 